\title{
Boiled coffee fails to raise serum cholesterol in hamsters and
}

\section{rats}

\author{
BY ANTON C. BEYNEN \\ Department of Laboratory Animal Science, Faculty of Veterinary Medicine, Utrecht University, \\ Utrecht, The Netherlands
}

\author{
AND MARIANNE P. M. E. WEUSTEN-VAN DER WOUW, BAUKJE DE ROOS \\ AND MARTIJN B. KATAN \\ Department of Human Nutrition, Agricultural University, Wageningen, The Netherlands
}

(Received 3 August 1994 - Revised 12 February 1996 - Accepted 16 February 1996)

\begin{abstract}
Boiled coffee contains the lipid compounds cafestol and kahweol, which raise cholesterol strongly in man. These lipids are retained by paper filters. In a search for an animal model for the effect of coffee lipids on serum cholesterol concentrations, we fed hamsters (Mesocricetus auratus) and rats on mash diets consisting of a purified base diet and either boiled water, unfiltered boiled coffee or filtered boiled coffee. After a feeding period of 8 weeks there was no statistically significant effect of unfiltered boiled coffee on serum total cholesterol and triacylglycerol concentrations in either the hamsters or the rats. The level of serum cholesterol did respond predictably to the addition of cholesterol and/or saturated fatty acids to the diet. The lack of effect of unfiltered boiled coffee in the hamsters and the rats, when compared with the previously reported activity in humans, could not be explained by dosage, duration of treatment, mode of administration or by insufficient statistical power. It is concluded that hamsters and rats are insensitive to unfiltered boiled coffee and thus are unsuitable models for investigating its hypercholesterolaemic effect.
\end{abstract}

Coffee: Serum cholesterol: Animal model

The consumption of unfiltered, Scandinavian-style boiled coffee is associated with elevated levels of serum cholesterol (Thelle et al. 1983; Stensvold et al. 1989; Pietinen et al. 1990). Controlled experiments in man have confirmed that unfiltered boiled coffee raises serum total and LDL-cholesterol concentrations (Aro et al. 1987; Bak \& Grobbee, 1989; Van Dusseldorp et al. 1991). Unlike filtered coffee, unfiltered boiled coffee contains a small amount of lipid, which contains the factor that causes the hypercholesterolaemic effect of boiled coffee (Zock et al. 1990). This factor is retained by a paper filter (Ahola et al. 1991; Van Dusseldorp et al. 1991). We recently identified the diterpenes cafestol and kahweol as the responsible factors in unfiltered boiled coffee (Weusten-Van der Wouw et al. 1994).

The availability of an animal model for the effect of boiled coffee on serum cholesterol concentration would be of great value in unravelling the underlying mechanism. In our hands the feeding of freeze-dried, boiled coffee to hamsters or gerbils did not affect serum cholesterol concentrations (Mensink et al. 1992). However, Sanders and Sandaradura (1992) reported that boiled coffee, given as the only source of drinking water, raised serum cholesterol concentrations in Syrian hamsters. We have therefore repeated our study in hamsters using liquid boiled coffee, because freeze drying, conceivably, might have removed or modified the diterpenes in our previous experiment (Mensink et al. 1992). As 
the rat is the most commonly used animal in experimental nutrition (Beynen \& West, 1986), we also tested the effect of boiled coffee on serum cholesterol concentrations in rats.

\section{MATERIALS AND METHODS}

The experimental protocols were approved and their conduct supervised by the animal welfare officer of the Wageningen Agricultural University.

\section{Animals and housing}

Male Syrian hamsters (Mesocricetus auratus; HsdCpb:ShGa) aged 4 weeks and female Wistar rats (Rattus norvegicus; HsdCpb:WU) aged 3 weeks were purchased from Harlan/CPB, Zeist, The Netherlands. On arrival they were housed in groups of five animals of the same species in polycarbonate cages with a wire top and a layer of sawdust as bedding. The cages were placed in a room with controlled lighting (light on: $06.00-18.00$ hours), temperature $\left(20-22^{\circ}\right)$, relative humidity $(50-55 \%)$ and ventilation $(20$ air changes $/ \mathrm{h}$ ).

\section{Experimental design and diets}

The experiment with hamsters comprised seven groups of thirteen animals each. The diets were supplied in the form of a mash containing a base diet with or without added cholesterol and either boiled coffee, boiled-and-filtered coffee or boiled water $(1: 1, \mathrm{w} / \mathrm{w})$. The cholesterol-rich diets were included in an attempt to enhance the cholesterolaemic response to boiled coffee. In various experimental animals the influence of feed components on serum cholesterol is greater with a dietary background rich in cholesterol (Beynen \& West, 1989). The composition of the base diets was as follows $(\mathrm{g} / \mathrm{kg})$ : casein 151 , maize oil $47 \cdot 5$, coconut fat $47 \cdot 5$, cholesterol 0 or 0.5 , maize starch 344.4 or 343.9 , glucose 300 , cellulose $50, \mathrm{CaCO}_{3} 12 \cdot 4, \mathrm{NaH}_{2} \mathrm{PO}_{4} .2 \mathrm{H}_{2} \mathrm{O} 15 \cdot 1, \mathrm{MgCO}_{3} 1 \cdot 4 ; \mathrm{KCl} 1 \cdot 0, \mathrm{KHCO}_{3} 7 \cdot 7$, mineral premix $10 \cdot 0$, vitamin premix $12 \cdot 0$. The composition of the mineral and vitamin premixes has been reported elsewhere (Hoek et al. 1988). The seventh group served as an additional positive control; it received a diet which was high in saturated fatty acids, which are known to raise serum cholesterol levels in hamsters (Spady \& Dietschy, 1985; Ohtani et al. 1990). The diet high in saturated fatty acids was formulated by adding $152.5 \mathrm{~g}$ coconut fat $/ \mathrm{kg}$ to the cholesterol-free base diet at the expense of an isoenergetic amount of maize starch-glucose $(1: 1, \mathrm{w} / \mathrm{w})$. Table 1 shows the analysed composition of the diets.

The experiment with rats comprised six groups of twelve animals each. The diets were supplied in the form of a mash containing a base diet with or without added cholesterol and boiled coffee, boiled-and-filtered coffee or boiled water $(4: 1, w / w)$. The composition of the base diets was as follows $(\mathrm{g} / \mathrm{kg})$ : casein 210 , maize oil 100 , coconut fat 100 , cholesterol 0 or 10 , sucrose $460 \cdot 4$ or $450 \cdot 4$, molasses 50 , cellulose $20, \mathrm{CaCO}_{3} 12 \cdot 4, \mathrm{NaH}_{2} \mathrm{PO}_{4} \cdot 2 \mathrm{H}_{2} \mathrm{O} 15 \cdot 1$, $\mathrm{MgCO}_{3} 1 \cdot 4, \mathrm{KCl} 1 \cdot 0, \mathrm{KHCO}_{3} 7 \cdot 7$, mineral premix $10 \cdot 0$, vitamin premix $12 \cdot 0$. The amount of added cholesterol is known to raise serum cholesterol concentrations in female rats (Beynen, 1987). Table 2 shows the analysed composition of the diets.

Boiled coffee was prepared by pouring $500 \mathrm{ml}$ boiling water onto $50 \mathrm{~g}$ commercially available coarsely ground coffee (Roodmerk ${ }^{*}$, Douwe Egberts, Utrecht, The Netherlands) in a thermos flask. We showed previously that such coffee raises serum cholesterol concentrations in man (Van Dusseldorp et al. 1991). The grounds were allowed to settle for $15 \mathrm{~min}$ and the brew was decanted into another thermos flask. To prepare boiled-andfiltered coffee, the boiled coffee was poured through a white paper filter (no. 4, Melitta Nederland, Veenendaal, The Netherlands) held in a conical plastic holder. When mixed with the base diets, the boiled water, boiled coffee and boiled-and-filtered coffee had a temperature of $50-70^{\circ}$. 
Table 1. Analysed composition of the mash diets used in the experiment with hamsters

\begin{tabular}{|c|c|c|c|c|c|c|c|}
\hline & \multicolumn{3}{|c|}{ Cholesterol-free diets } & \multicolumn{3}{|c|}{ High-cholesterol diets } & \multirow[b]{2}{*}{$\begin{array}{l}\text { High-fat, } \\
\text { cholesterol- } \\
\text { free diet }\end{array}$} \\
\hline & Water & $\begin{array}{l}\text { Filtered } \\
\text { coffee }\end{array}$ & $\begin{array}{l}\text { Unfiltered } \\
\text { coffee }\end{array}$ & Water & $\begin{array}{l}\text { Filtered } \\
\text { coffee }\end{array}$ & $\begin{array}{l}\text { Unfiltered } \\
\text { coffee }\end{array}$ & \\
\hline Dry matter $(\mathrm{g} / \mathrm{kg})$ & 484 & 483 & 488 & 462 & 482 & 491 & 467 \\
\hline Ash $(g / k g)$ & 14 & 16 & 16 & 14 & 16 & 16 & 17 \\
\hline Fat $(\mathrm{g} / \mathrm{kg})$ & 56 & 59 & 64 & 54 & 57 & 62 & 162 \\
\hline Nitrogen $(\mathrm{g} / \mathrm{kg})$ & 11 & 11 & 12 & 11 & 11 & 11 & 13 \\
\hline Cholesterol $(\mathrm{g} / \mathrm{kg})$ & 0.04 & 0.05 & 0.05 & 0.26 & 0.31 & 0.33 & 0.06 \\
\hline Cafestol $(\mathrm{mg} / \mathrm{kg})$ & ND & ND & $44 \cdot 1$ & ND & ND & $45 \cdot 1$ & ND \\
\hline Kahweol (mg/kg) & ND & ND & $45 \cdot 4$ & ND & ND & $43 \cdot 2$ & ND \\
\hline \multicolumn{8}{|l|}{$\begin{array}{l}\text { Fatty acids ( } \mathrm{g} / \mathrm{kg} \\
\text { fatty acid methyl } \\
\text { esters) }\end{array}$} \\
\hline $12: 0$ & 235 & 231 & 224 & 222 & 222 & 219 & 369 \\
\hline $14: 0$ & 92 & 90 & 88 & 87 & 87 & 86 & 142 \\
\hline $16: 0$ & 100 & 100 & 104 & 101 & 100 & 104 & 99 \\
\hline $18: 0$ & 179 & 179 & 177 & 182 & 182 & 180 & 117 \\
\hline $18: 2$ & 274 & 275 & 279 & 278 & 283 & 286 & 125 \\
\hline
\end{tabular}

ND, not detectable.

Table 2. Analysed composition of the mash diets used in the experiment with rats

\begin{tabular}{|c|c|c|c|c|c|c|}
\hline & \multicolumn{3}{|c|}{ Cholesterol-free diets } & \multicolumn{3}{|c|}{ High-cholesterol diets } \\
\hline & Water & $\begin{array}{c}\text { Filtered } \\
\text { coffee }\end{array}$ & $\begin{array}{l}\text { Unfiltered } \\
\text { coffee }\end{array}$ & Water & $\begin{array}{l}\text { Filtered } \\
\text { coffee }\end{array}$ & $\begin{array}{l}\text { Unfiltered } \\
\text { coffee }\end{array}$ \\
\hline Dry matter $(\mathrm{g} / \mathrm{kg})$ & 777 & 783 & 784 & 780 & 786 & 787 \\
\hline Ash $(\mathrm{g} / \mathrm{kg})$ & 27 & 28 & 28 & 27 & 28 & 28 \\
\hline Fat $(\mathrm{g} / \mathrm{kg})$ & 176 & 172 & 174 & 179 & 181 & 178 \\
\hline Nitrogen $(\mathrm{g} / \mathrm{kg})$ & 25 & 25 & 24 & 25 & 25 & 25 \\
\hline Cholesterol $(\mathrm{g} / \mathrm{kg})$ & 0.01 & 0.01 & 0.01 & 7.99 & 7.78 & $7 \cdot 61$ \\
\hline \multicolumn{7}{|c|}{$\begin{array}{l}\text { Fatty acids ( } \mathrm{g} / \mathrm{kg} \text { fatty acid } \\
\text { methyl esters) }\end{array}$} \\
\hline $12: 0$ & 230 & 230 & 229 & 232 & 232 & 231 \\
\hline $14: 0$ & 90 & 90 & 90 & 91 & 91 & 91 \\
\hline $16: 0$ & 100 & 100 & 101 & 100 & 100 & 101 \\
\hline $18: 0$ & 181 & 182 & 181 & 175 & 175 & 175 \\
\hline $18: 2$ & 291 & 290 & 292 & 295 & 295 & 294 \\
\hline
\end{tabular}

All hamsters and rats went through a run-in period of 2 weeks during which they received the cholesterol-free base diet mixed with boiled water. Then, on day 0 of the experiment, the animals were allocated to the dietary groups which were stratified for body weight and serum cholesterol concentration. For the next 8 weeks the hamsters received the seven and the rats the six experimental mash diets. During the experimental period the hamsters and the rats were housed individually. The animals had free access to the mash diets and tap water. Feed intake, water intake and body weight were recorded. The mash diets were prepared three times weekly and stored at $4^{\circ}$ until used for feeding. The base diets, which were in powdered form, were kept at $4^{\circ}$. 


\section{Collection of samples}

Blood was sampled by orbital puncture on day 0 and after $2,4,6$ and 8 weeks, between 09.00 and 11.00 hours, while the animals were under light diethyl-ether anaesthesia. Feed was not withheld before sampling. Serum was obtained by low-speed centrifugation $(3000 \mathrm{~g}, 10 \mathrm{~min})$ and stored at $-20^{\circ}$ until analysis. At the end of the experiment the anaesthetized animals were killed by decapitation immediately after blood sampling. Livers were removed, weighed and frozen at $-20^{\circ}$ until cholesterol analysis.

\section{Chemical analyses}

To obtain DM and ash contents of the mash diets, samples were incubated at $70^{\circ}(12 \mathrm{~h}$, vacuum oven) and $550^{\circ}(5 \mathrm{~h})$ respectively. $\mathrm{N}$ in samples of the mash diets was determined by the Kjeldahl method (Joslyn, 1970). Crude fat was determined by extraction according to the Soxhlet method (Joslyn, 1970), and fatty acids by GLC (Metcalfe et al. 1966).

Cholesterol in diet samples was determined by GLC (Nordby \& Nagy, 1973). In samples of the mash diets for the experiment with hamsters, the diterpene alcohols cafestol and kahweol were analysed in ether extracts by capillary GLC, and the purity of peaks was verified by mass spectrometry (Weusten-Van der Wouw et al. 1994).

Serum total cholesterol and triacylglycerols were determined enzymically with the use of commercial test combinations (CHOD-PAP and GPO kits, Boehringer-Mannheim GmbH, Mannheim, Germany). Mean bias for control serum (Precinorm, Boehringer-Mannheim) was $2.53 \%$ for cholesterol; the coefficient of variation within runs was on average $1.56 \%$. Liver total cholesterol was extracted and analysed according to the method of Abell et al. (1952). Serum activity of alanine aminotransferase (EC 2.6.1.2; ALAT) was measured at $37^{\circ}$ using a commercial kit (Unikit II, Roche Diagnostics, Mijdrecht, The Netherlands) and an autoanalyser (COBAS-BIO, Roche). The mean bias for a control serum (Roche P) was $6.98 \%$; the within-run coefficient of variation averaged $1.69 \%$.

\section{Statistics}

All data were found to be normally distributed (Kolmogorov-Smirnov test). The final data for the groups fed on diets containing either filtered or unfiltered coffee were evaluated with two-way ANOVA. The original data for the groups subjected to ANOVA had homogeneous variances (Levene test), except for liver cholesterol concentrations in the hamsters which first had to be transformed to their $\ln ^{-1}$ values, and the liver and final serum cholesterol concentrations in the rats which could not be transformed so as to obtain homogeneous variances. The latter two variables in the rats were evaluated with the use of Student's $t$ test. The groups fed on diets with boiled water served as reference and were not involved in the statistical analysis except for a priori defined comparisons with the groups given boiled coffee for which Student's $t$ test was used. The hamsters given the high-fat diet served as an extra positive control in addition to those fed on the high-cholesterol diets. The results of comparisons with either the reference groups or the positive control are not indicated in the tables, but given in the text. The level of statistical significance was pre-set at $P<0.05$.

\section{RESULTS}

\section{Body weight and feed intake}

Neither the presence of cholesterol in the diet nor the type of coffee significantly influenced final body weight and feed intake in either the hamsters or the rats (Table 3). Filtered and unfiltered boiled coffee $v$. water as reference reduced feed intake $(P<0.001)$ and body weight $(P<0.05)$ in the hamsters. In the rats, filtered and unfiltered boiled coffee $v$. the reference treatment had opposite effects $(P<0.05$ for feed intake and for body weight). Feed intake $(\mathrm{g} / \mathrm{d})$ was decreased in the hamsters fed on the diet high in coconut fat and as 
BOILED COFFEE AND SERUM CHOLESTEROL

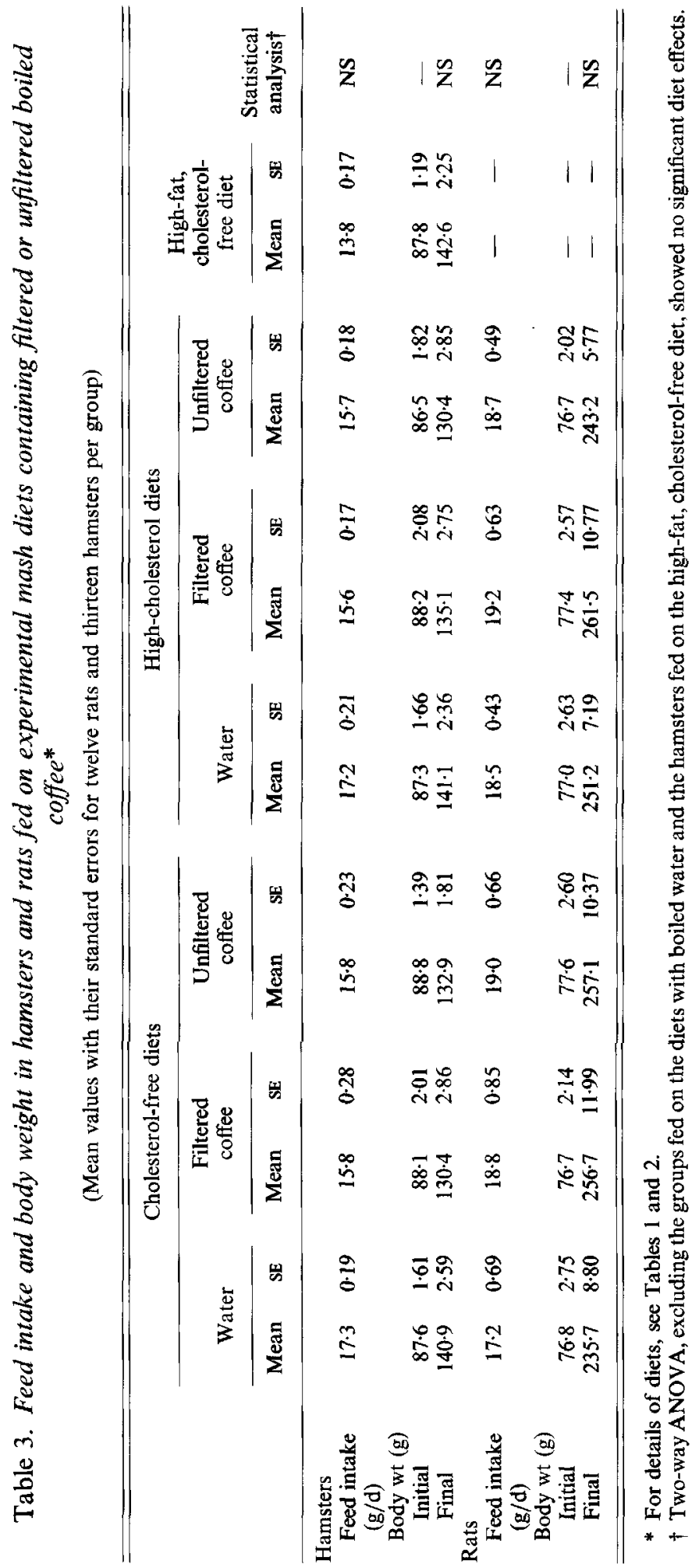




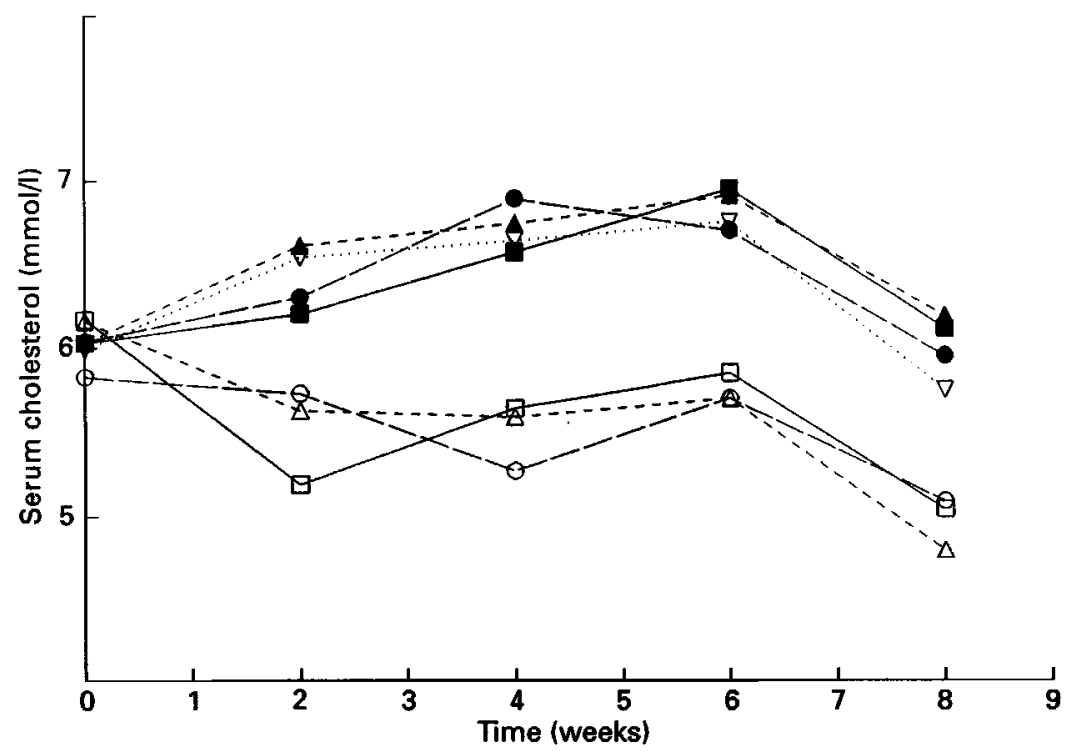

Fig. 1. Time course of group mean serum cholesterol concentrations in hamsters fed on the experimental mash diets. Cholesterol-free diets with boiled water $(\square)$, filtered boiled coffee $(O)$ or unfiltered boiled coffee $(\triangle)$; highcholesterol diets with boiled water $(\boldsymbol{D})$, filtered boiled coffee $(\Theta)$ or unfiltered boiled coffee $(\boldsymbol{\Lambda})$; high-fat diet $(\nabla)$. For details of diets and procedures see Table 1 and pp. 756-758.

a result, total energy intake (results not shown) and body weight were similar to the animals given the reference diet with boiled water.

\section{Serum cholesterol and triacylglycerols and liver cholesterol}

Figs 1 and 2 show the time courses of changes in serum cholesterol concentration. There was no effect of unfiltered $v$. filtered coffee on serum cholesterol in either hamsters or rats. On the other hand, the addition of cholesterol to the diet significantly raised serum total cholesterol concentrations in both hamsters and rats (Table 4). Consumption of the highsaturated-fat, positive control diet by the hamsters also produced a significant increase in serum cholesterol $(P<0.05)$, when compared with the cholesterol-free reference diet with boiled water.

Dietary cholesterol and the type of boiled coffee did not alter serum triacylglycerols in either the hamsters or the rats. Filtered or unfiltered coffee instead of boiled water as reference significantly reduced serum triacylglycerols in the hamsters $(P<0.01)$ but not in the rats (Table 4).

Cholesterol feeding significantly elevated liver weight in the hamsters and to a greater extent also in the rats (Table 4). Liver cholesterol concentrations were drastically increased after cholesterol loading, but were unaffected by unfiltered $v$. filtered coffee in both the hamsters and the rats.

\section{Serum alanine aminotransferase activity}

Because the ingestion of unfiltered boiled coffee in humans raised the serum activity of ALAT (Weusten-Van der Wouw et al. 1994), which is an indicator of liver function, this variable was also monitored in the present experiment with hamsters. After 8 weeks, neither cholesterol feeding nor unfiltered boiled coffee had a significant effect on ALAT activities. The mean ALAT activities during the entire experiment were as follows: cholesterol-free 


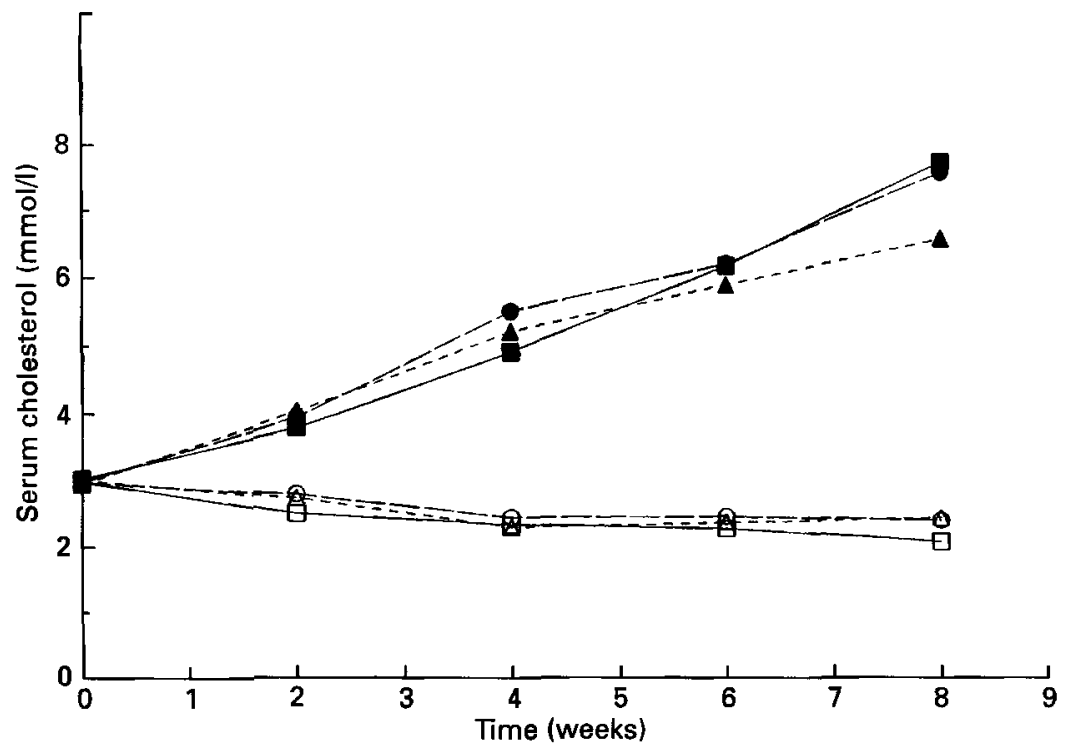

Fig. 2. Time course of group mean serum cholesterol concentrations in rats fed on the experimental mash diets. Cholesterol-free diets with boiled water $(\square)$, filtered boiled coffee $(O)$ or unfiltered boiled coffee $(\triangle)$; highcholesterol diets with boiled water $(\boldsymbol{\square})$, filtered boiled coffee $(\boldsymbol{O})$ or unfiltered boiled coffee $(\boldsymbol{\Delta})$. For details of diets and procedures see Table 2 and pp. 756-758.

diets with water, filtered and unfiltered coffee 111.05 (SE 51.51), 61.14 (SE 3.64) and 77.64 (SE 11.40), and high-cholesterol diets with water, filtered and unfiltered coffee 67.53 (SE 6.06), 110.27 (SE 31.26) and 71.40 (SE 6.91), and the high-fat diet 56.44 (SE 6.64) $\mathrm{U} / 1$.

\section{DISCUSSION}

In our hands unfiltered boiled coffee, when compared with filtered boiled coffee, did not significantly influence serum cholesterol and triacylglycerol concentrations in either hamsters or rats. In contrast, such unfiltered boiled coffee has repeatedly been shown to raise serum cholesterol and triacylglyerol concentrations in controlled trials with humans (Bak and Grobbee, 1989; Van Dusseldorp et al. 1991). As elaborated later, the lack of effect in the hamsters and rats cannot be attributed to a low dose of unfiltered boiled coffee, a short duration of challenge and a different mode of administration. Thus, there may be a species difference in that hamsters and rats are insensitive to unfiltered boiled coffee whereas humans are sensitive. The insensitivity of the hamsters and rats appears to be rather specific because they did respond predictably (Spady \& Dietschy, 1985; Beynen, 1987) to cholesterol and/or saturated fatty acids in the diet.

In human subjects consuming $10 \mathrm{MJ}$ energy/d the daily intake of eight cups (1 litre) of unfiltered boiled coffee, brewed with $50 \mathrm{~g}$ of ground coffee per litre of water, raises serum total cholesterol and triacylglycerol levels by about 0.5 and $1.0 \mathrm{mmol} / 1$ respectively (Aro et al. 1987; Bak \& Grobbee, 1989). The hamsters in the present experiment ingested the equivalent to forty and the rats the equivalent of nine cups per $10 \mathrm{MJ}$ diet, which can be considered sufficient to elicit an effect, if any. The present experiments lasted 8 weeks whereas in humans the hypercholesterolaemic effect of unfiltered boiled coffee can be demonstrated within 3-6 weeks (Aro et al. 1987; Bak \& Grobbee, 1989). For the hamsters and the rats we mixed the coffee brews with the base diet to provide the mixture in the form 


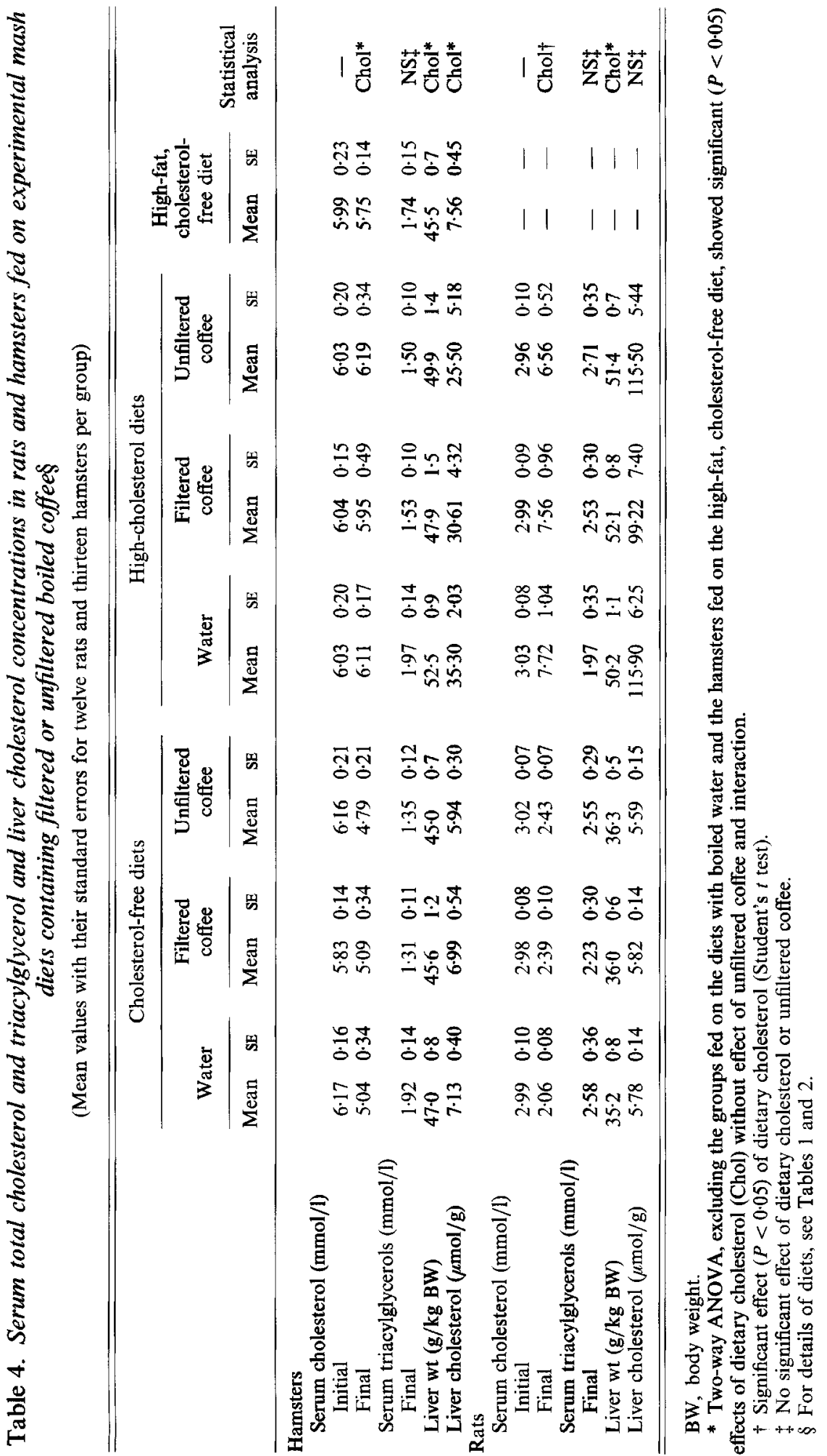


of a mash. It could be argued that the cholesterol-raising factor of unfiltered boiled coffee is rendered inoffensive by some unknown interaction between the brew and diet. However, this possibility is unlikely. Cafestol and kahweol, which have recently been identified as the hypercholesterolaemic principles of unfiltered boiled coffee (Heckers et al. 1994; WeustenVan der Wouw et al. 1994), were found to be present at expected levels in the mash diets with unfiltered boiled coffee (Table 1).

Sanders \& Sandaradura (1992) gave hamsters unfiltered boiled coffee as the only source of drinking water for a period of 4 weeks, and found that serum total cholesterol concentrations were raised by $0.78 \mathrm{mmol} / 1(16.9 \%)$ when compared with a sucrose solution. The intake of unfiltered boiled coffee was equivalent to twenty-eight cups $(125 \mathrm{ml} / \mathrm{cup} ; 50 \mathrm{~g}$ ground coffee $/ 1)$ per $10 \mathrm{MJ}$ dietary energy. Thus, the coffee challenge in our hamsters was heavier. With the observed residual variance of serum cholesterol concentration, the smallest statistically significant $(P<0.05)$ effect would be $0.54 \mathrm{mmol} / 1$ $(9.8 \%)$ at a statistical power of $80 \%$. This calculated difference, which would be reasonably detectable, is smaller than that observed by Sanders \& Sandaradura (1992). Clearly, the absence of a hypercholesterolaemic effect of unfiltered boiled coffee in our hamsters cannot be explained by low dosage or by unsufficient statistical power. Sanders \& Sandaradura (1992) noted that the cholesterol-raising effect of unfiltered boiled coffee was not seen against the background of a commercial, cholesterol-free natural-ingredient diet. Half of our diets contained cholesterol, but those used in the experiment with hamsters contained less saturated fatty acid than the diet of Sanders \& Sandaradura (1992). Our diets contained no sucrose whereas those of Sanders \& Sandaradura (1992) contained about $110 \mathrm{~g} / \mathrm{kg} \mathrm{DM}$. Perhaps the use of different background diets caused the discrepancy between the present results and those of Sanders \& Sandaradura (1992). The present experiment with hamsters does confirm our earlier work showing that the feeding of freeze-dried, unfiltered boiled coffee had no effect on serum cholesterol concentrations in hamsters (Mensink et al. 1992). It cannot be excluded, however, that the strain of hamsters used determines the sensitivity of unfiltered boiled coffee. Different strains of hamsters can show different cholesterolaemic responses to diet (Trautwein et al. 1993).

We conclude that hamsters and rats are relatively insensitive to the cholesterol-raising effect of cafestol and kahweol from unfiltered boiled coffee as seen in humans. This conclusion is substantiated by the observed lack of effect of unfiltered boiled coffee on serum ALAT activities which have been shown recently to be increased in human subjects after drinking boiled but not filtered coffee (Weusten-Van der Wouw et al. 1994). It is possible that the mechanisms underlying the effects of unfiltered boiled coffee on cholesterol metabolism and liver function can be studied in humans only.

These studies were supported by the Netherlands Heart Foundation through grant No. 900-562-091 of the Netherlands Organization for Scientific Research (NWO). We thank Gerrit Van Tintelen, Robert Hovenier and Inez Lemmens for expert technical assistance.

\section{REFERENCES}

Abell, L. L., Levy, B. B., Brodie, B. B. \& Kendall, F. E. (1952). A simplified method for the estimation of total cholesterol in serum and demonstration of its specificity. Journal of Biological Chemistry 195, 357-366.

Ahola, I., Jauhiainen, M., \& Aro, A. (1991). The hypercholesterolaemic factor in boiled coffee is retained by a paper filter. Journal of Internal Medicine 230, 293-297.

Aro, A., Tuomilehto, J., Kostiainen, E., Uusitalo, U. \& Pietinen, P. (1987). Boiled coffee increases serum low density lipoprotein concentration. Metabolism 36, 1027-1030.

Bak, A. A. A., \& Grobbee, D. E. (1989). The effect on serum cholesterol of coffee brewed by filtering or boiling New England Journal of Medicine 321, 1432-1437.

Beynen, A. C. (1987). Serum and liver cholesterol in rats fed cholesterol-free or high-cholesterol diets differing in type and amount of fat. Nutrition Reports International 35, 1327-1332. 
Beynen, A. C. \& West, C. E. (1986). The suitability of animal models for research in human nutrition: a workshop report. In Proceedings XIII International Congress of Nutrition, pp. 58-59 [T. G. Taylor and N. K. Jenkins, editors]. London: John Libbey \& Company Ltd.

Beynen, A.C. \& West, C.E. (1989). Mechanisms underlying nutritional effects on serum cholesterol concentrations. In Coronaries and Cholesterol, pp. 89-114 [W. J. Cliff and G. I. Schoefl, editors]. London: Chapman and Hall Medical.

Heckers, H., Göbel, U. \& Kleppel, U. (1994). End of the coffee mystery: diterpene alcohols raise serum lowdensity lipoprotein cholesterol and triglyceride levels. Journal of Internal Medicine 235, 192-193.

Hoek, A. C., Lemmens, A. G., Mullink, J. W. M. A. \& Beynen, A. C. (1988). Influence of dietary calcium:phosphorus ratio on mineral excretion and nephrocalcinosis in female rats. Journal of Nutrition 118, $1210-1216$.

Joslyn, M. A. (1970). Methods in Food Analysis, 2nd ed. New York: Academic Press.

Mensink, R. P., Zock, P. L., Katan, M. B. \& Beynen, A. C. (1992). Boiled coffee does not increase serum cholesterol in gerbils and hamsters. Zeitschrift für Ernährungswissenschaft 31, 82-85.

Metcalfe, L. D., Schmitz, A. A. \& Pelka, J. R. (1966). Rapid separation of fatty acid esters from lipids for gas chromatography analysis. Analytical Chemistry 18, 514-515.

Nordby, H. E. \& Nagy, S. (1973). An evaluation of recent gas-liquid chromatographic liquid phases for resolution of acetylated plant sterols. Journal of Chromatography 75, 187-193.

Ohtani, H., Hayashi, K., Hirata, Y., Dojo, S., Nakashima, K., Nishio, E., Kurushima, H., Saeki, M. \& Kajiyama, G. (1990). Effects of dietary cholesterol and fatty acids on plasma cholesterol level and hepatic lipoprotein metabolism. Journal of Lipid Research 31, 1413-1422.

Pietinen, P., Aro, A., Tuomilehto, J., Uusitalo, U. \& Korhonen, H. (1990). Consumption of boiled coffee is correlated with serum cholesterol in Finland. International Journal of Epidemiology 19, 586-590.

Sanders, T. A. B. \& Sandaradura, S. (1992). The cholesterol-raising effect of coffee in the Syrian hamster. British Journal of Nutrition 68, 431-434.

Spady, D. K. \& Dietschy, J. M. (1985). Dietary saturated triacylglycerols suppress hepatic low density lipoprotein receptor activity in the hamster. Proceedings of the National Academy of Sciences USA 82, 4526-4530.

Stensvold, I., Tverdal, A. \& Foss, O. P. (1989). The effect of coffee on blood lipids and blood pressure. Results from a Norwegian cross-sectional study, men and women, 40-42 years. Journal of Clinical Epidemiology 42, 877-884.

Thelle, D. S., Arnesen, E. \& Førde, O. H. (1983). The Tromsø Heart Study. Does coffee raise serum cholesterol? New England Journal of Medicine 308, 1454-1457.

Trautwein, E. A., Liang, J. S. \& Hayes, K. C. (1993). Cholesterol gallstone induction in hamsters reflects strain differences in plasma lipoproteins and bile acid profiles. Lipids 28, 305-312.

Van Dusseldorp, M., Katan, M. B., Van Vliet, T., Demacker, P. N. M. \& Stalenhoef, A. F. H. (1991). Cholesterol-raising factor from boiled coffee does not pass a paper filter. Arteriosclerosis and Thrombosis 11, 586-593.

Weusten-Van der Wouw, M. P. M. E., Katan, M. B., Viani, R., Hugget, A. C., Liardon, R., Lund-Larsen, P. G., Thelle, D. S., Ahola, I., Aro, A., Meyboom, S. \& Beynen, A. C. (1994). The identity of the cholesterol-raising factor from unfiltered boiled coffee, and its effects on liver function enzymes. Journal of Lipid Research 35, 721-733.

Zock, P. L., Katan, M. B., Merkus, M. P., Van Dusseldorp, M. \& Harryvan, J. L. (1990). Effect of a lipid-rich fraction from boiled coffee on serum cholesterol. Lancet 335, 1235-1237. 